\title{
INDEPENDENT REGRESSION OF NORMAL AND INDUCED CORPORA LUTEA IN HYSTERECTOMIZED GUINEA-PIGS
}

\author{
R. DEANESLY AND J. S. PERRY \\ A.R.C. Institute of Animal Physiology, \\ Babraham, Cambridge
}

(Received 18th April 1969)

\begin{abstract}
Summary. The original corpora lutea were examined and measured in twenty-one guinea-pigs still in the luteal phase 55 to 116 days after hysterectomy. Most corpora lutea had regressed to less than half their average maximum volume after 70 days and all had regressed after 80 days. The luteal phase may last for 150 days or more, although ovulation may sometimes occur spontaneously between 79 and 90 days after hysterectomy. Possible reasons for the prolonged anoestrus are discussed.

In previous experimental work, existing hysterectomy corpora lutea remained unaffected for 14 to 18 days by induced corpora lutea in the same ovaries. In a fresh series killed 51 to 72 days after hysterectomy, the original corpora lutea had regressed in six out of nine females and, except for a remnant, had disappeared in another, while the induced corpora lutea remained large 21 to 33 days after ovulation. It was concluded that the original corpora lutea regressed according to their age, asynchronously with the induced ones, as in similar experiments on hysterectomized sheep. No uterine luteolytic hormone could be involved, but a more active metabolism in the more recent corpora lutea might be postulated.
\end{abstract}

\section{INTRODUCTION}

The formation of a new set of corpora lutea can be induced by the administration of luteinizing hormone $(\mathrm{LH})$, or other gonadotrophins, when the original corpora lutea are still functional. In preliminary experiments, this has been shown for both the cyclic and hysterectomized guinea-pig (Deanesly 1966). In the pig (Neill \& Day 1964), if the new corpora lutea were not induced very early in the cycle, they survived the original corpora lutea for about one cycle length and prolonged the luteal phase. In hysterectomized pigs, both sets of corpora lutea still persisted at autopsy 50 days after hysterectomy. The authors concluded that selective regression of corpora lutea was partially dependent on their age.

In the sheep, Inskeep, Oloufa, Pope \& Casida (1963) found that induced corpora lutea regressed at the same time as the original ones and did not extend cycle length. In hysterectomized sheep, however, Kiracofe \& Spies 
(1966) observed independent regression of the induced and original corpora lutea, the former remaining large and functional while the latter regressed at about the normal time. All nine untreated, hysterectomized ewes had regressed corpora lutea when examined at 160 to 169 days; of these, two had come on oestrus and one had ovulated. The others had regressed corpora lutea only but 40 days later all had ovulated without oestrus. Ovulation without oestrus was also found in sheep hysterectomized during anoestrus.

In view of the problems of the control of the extended luteal phase in hysterectomized females, it was decided to study the maintenance or regression of the original and induced corpora lutea in the guinea-pig after the first 50 days of the hysterectomy luteal phase.

\section{MATERIALS AND METHODS}

\section{Animals and operations}

The guinea-pigs were from the stock maintained at this Institute. Hysterectomy was performed by a mid-ventral incision under Avertin and ether anaesthesia, 4 to 6 days after the estimated time of ovulation. The caudal segment of the cervix was tied off and both uterine horns were removed together with the anterior part of the cervix, the cut being made just above the level at which the separate uterine lumina join. The main uterine artery and vein of each side were preserved. The animals were subsequently maintained in small groups in cages, and the vagina was examined daily. The luteinizing hormone was NIH-LH-s.10.

Histology. Ovaries were fixed in Bouin's or freshly prepared Ciaccio's fluid ( $5 \%$ potassium bichromate, $8 \mathrm{ml} ; 40 \%$ formalin, $2 \mathrm{ml}$; acetic acid, $0.5 \mathrm{ml}$ ); the latter were post-chromed for 3 days, washed overnight in running water, dehydrated and embedded normally. All ovaries were cut serially at $7 \mu$ and every sixth section mounted. Staining was in haematoxylin and eosin. Ciaccio's method preserves ovarian lipids; these were stained with Oil Red $\mathrm{O}$, the sections being mounted in glycerine jelly. The vagina was fixed in Bouin's fluid and sections were stained with haematoxylin and eosin.

Measurements. Determinations of corpus luteum size were made by measuring two diameters at right angles across the largest sections through each corpus luteum, and calculating the third diameter from the number of sections in which the corpus luteum appeared (Deanesly, 1967). The average of these three diameters was then taken as the individual mean diameter. For regressing corpora lutea which were no longer spherical, the mean diameter might over-estimate the volume as compared with that of others, but in general it gives a close approximation to the size of the corpus luteum. The volume can be obtained by multiplying the cube of the mean diameter by $0.524(\pi / 6)$.

\section{RESULTS}

NORMAL REGRESSION OF CORPORA LUTEA OF HYSTERECTOMY AND THE ANOVULATION PERIOD

The corpora lutea of hysterectomy in the guinea-pig are similar in size to fully 
developed corpora lutea of pregnancy, attaining a mean diameter of 1.80 to $2.15 \mathrm{~mm}$. The average of the mean diameters of thirty-six large hysterectomy corpora lutea was $1.93 \mathrm{~mm}$, representing a volume of $3.76 \mathrm{~mm}^{3}$; since a mean diameter of $1.7 \mathrm{~mm}$, representing a volume of $2.57 \mathrm{~mm}^{3}$, would be nearly $30 \%$ smaller, hysterectomy corpora lutea below this size have been arbitrarily classed as 'regressing' in this paper in agreement with their appearance in sections. Histological signs of regression include the shape of the corpora lutea, the size and arrangement of their lutein cells, the rarity or absence of mitotic figures and changes in the vascularization. The lipid content of the lutein cells varies little after the first 40 days of the hysterectomy period.

TABLE 1

CORPORA LUTEA OF HYSTERECTOMY 55 TO 116 DAYS AFTER OPERATION

\begin{tabular}{c|c|c|c}
\hline $\begin{array}{c}\text { Guinea-pig } \\
\text { no. }\end{array}$ & $\begin{array}{c}\text { Days after } \\
\text { hysterectomy }\end{array}$ & $\begin{array}{c}\text { No. of } \\
\text { corpora } \\
\text { lutea }\end{array}$ & $\begin{array}{c}\text { Av. of mean } \\
\text { diam. }(m m)\end{array}$ \\
\hline PH 74 & 55 & 1 & 1.28 \\
80 & 55 & 3 & 1.84 \\
81 & 55 & 4 & 1.85 \\
63 & 60 & 3 & 1.80 \\
56 & 62 & 2 & 1.47 \\
62 & 68 & 2 & 1.01 \\
64 & 68 & 3 & 1.83 \\
75 & 69 & 4 & 1.73 \\
65 & 70 & 3 & 1.37 \\
66 & 70 & 1 & 1.85 \\
86 & 72 & 4 & 1.42 \\
83 & 76 & 4 & 1.67 \\
68 & 80 & 4 & 1.60 \\
$67 *$ & 80 & 4 & 1.84 \\
$44 \dagger$ & 81 & 1 & 1.40 \\
84 & 83 & 3 & 1.48 \\
69 & 91 & 3 & 1.58 \\
91 & 95 & 3 & 1.40 \\
70 & 106 & 4 & 1.42 \\
71 & 116 & 3 & 1.38 \\
72 & 116 & 3 & 1.14 \\
\hline
\end{tabular}

* Laparotomy at 37 days after hysterectomy; possibly a fresh ovulation.

$\dagger$ One ovary only examined.

Table 1 shows that out of fourteen females killed up to 80 days after operation, seven had regressed corpora lutea from Day 55 onwards and, in five of these, the volumes were less than 20 to $50 \%$ of the average maximum. After Day 80, all corpora lutea in the seven females were regressed (cf. Rowlands, 1961). No vaginal opening had occurred, except for a partial opening at 53 days in PH 74, the first animal in Table 1. This animal had not ovulated, but the ovaries contained large degenerating follicles and one regressed corpus luteum; in some areas, the mucified vaginal epithelium was breaking down. Another female, not listed in Table 1 since the original corpora lutea had disappeared except for a single remnant, had large recent corpora lutea 95 days after hysterectomy. It was concluded that spontaneous ovulation had occurred 
without vaginal oestrus or when the vaginal condition was accidentally unrecorded, 79 days after hysterectomy. An ovulation was also found in a female 84 days after hysterectomy; this animal had been treated with progesterone and oestradiol early in the luteal phase without obvious effect, and the ovulation with vaginal opening took place 50 days after the end of the experimental period.

Loeb (1927) records finding new ('7-day') corpora lutea in the guinea-pig 36 days after hysterectomy and Fischer (1967) observed the same after a 97-day cycle. Allowing for the more gradual regression of corpora lutea of hysterectomy as compared with those of pregnancy, the two types start to degenerate at about the same age (cf. Rowlands, 1961), although the former show more variability and the anovulatory period may be much prolonged (Howe, 1965).

Many ovaries in this series had normal or degenerating follicles of oestrous size, but from the continued inhibition of ovulation, presumably by progesterone

TABLE 2

CORPORA LUTEA OF HYSTEREGTOMY 21 TO 33 DAYS AFTER INDUCED OVULATION

\begin{tabular}{|c|c|c|c|c|c|c|}
\hline \multirow[b]{2}{*}{$\begin{array}{c}\text { Guinea-pig } \\
\text { no. }\end{array}$} & \multirow{2}{*}{\multicolumn{2}{|c|}{$\begin{array}{c}\text { Autopsy performed: } \\
\text { Days after } \\
\text { hysterctomy } \\
\text { hafter } \\
\text { LH }\end{array}$}} & \multicolumn{2}{|c|}{ Corpora lutea of hysterectomy } & \multicolumn{2}{|c|}{$\begin{array}{c}\text { Induced } \\
\text { corpora lutea* }\end{array}$} \\
\hline & & & No. & Mean diameters $(\mathrm{mm})$ & No. & $\underset{(m m)}{\operatorname{Max} \text { diam. }}$ \\
\hline $\begin{array}{r}\text { PH } 54 \\
89 \\
90 \\
58 \\
59 \\
87 \\
88 \\
55 \\
20\end{array}$ & $\begin{array}{l}51 \\
64 \\
64 \\
57 \\
57 \\
72 \\
72 \\
63 \\
54\end{array}$ & $\begin{array}{l}21 \\
21 \\
21 \\
28 \\
28 \\
28 \\
28 \\
32 \\
33\end{array}$ & $\begin{array}{l}4 \\
4 \\
4 \\
3 \\
4 \\
4 \\
4 \\
1 \\
3 \\
3\end{array}$ & $\begin{array}{l}1.53,1.46,1.47,1.63 \\
1.49,1.44,1.43,1.12 \\
1.58,1.55,1.40,1.37 \\
1.79,1.82,1.92 \\
1.88,1.93,1.76,1.75 \\
1.53,1.32,1.30,1.06 \\
1.20,1.09,1.05,1.01 \\
\text { Remnant only } \\
1 \cdot 18,0.85,0.93\end{array}$ & $\begin{array}{l}2 \\
4 \\
3 \\
6 \\
2 \\
4 \\
2 \\
5 \\
5\end{array}$ & $\begin{array}{l}1.69 \\
1.94 \\
1.85 \\
1.92 \\
1.93 \\
1.77 \\
1.86 \\
1.99 \\
1.84\end{array}$ \\
\hline
\end{tabular}

* These diameters are included to show the full development of the induced corpora lutea.

(Deanesly, 1968) and from the mucification of the vaginal epithelium up to 116 days after hysterectomy, it appears that the partially regressed corpora lutea are still secreting progesterone. Alternatively, another progestagen may be produced by the lipid-containing interstitial cells during corpora lutea degeneration, as in the rabbit (Hilliard, Spies \& Sawyer, 1968).

Removal of the ovaries from two guinea-pigs 43 and 55 days after hysterectomy caused the disappearance of the mucified vaginal epithelium within 11 days, showing that ovarian hormones were responsible for the maintenance, which requires both progesterone and oestrogen. After ovariectomy, the vaginal epithelium was low.

\section{CORPORA LUTEA OF HYSTEREGTOMY AFTER INDUCED OVULATION}

It was found in earlier experiments that induced corpora lutea could reach full hysterectomy size in 14 days without causing regression of the original corpora 
lutea of hysterectomy. Up to 56 days after hysterectomy, the original corpora lutea were still of maximum normal size in five out of seven hysterectomized guinea-pigs, in which treatment with LH had induced fresh corpora lutea 7 to 18 days earlier (Deanesly, 1966). In the other two females, 36 and 52 days after hysterectomy, the original corpora lutea were not up to full size, but this probably represented normal variation rather than the effects of induced ovulations.

Table 2 lists a further nine guinea-pigs which were killed 21 to 33 days after LH injection and 51 to 72 days after hysterectomy. In seven of them, the original corpora lutea had regressed, while the induced ones (except in PH 54), though more variable than the originals, included full size, histologically recent corpora lutea. In the other females (PH 58 and 59), two types of corpora lutea were seen at autopsy but, in sections, the differences were slight. All appeared functional 57 days after hysterectomy and the lutein cells had a similar lipid content.

These results suggest that it is the age of the original hysterectomy corpora lutea which is still the main factor in determining their regression; after 63 days, those in Table 2 perhaps show accelerated regression compared with those in Table 1, but the numbers are small. The induced corpora lutea have no discernible effect on the original corpora lutea until at least 21 days after their formation.

\section{DISCUSSION}

The duration of the hysterectomy luteal phase in the guinea-pig is variable and indefinite; full oestrus with vaginal opening and ovulation may not occur for 120 days or more after removal of the uterus. The present material shows that the corpora lutea can begin to regress from 55 days after hysterectomy, though some were still full-sized at 70 and 80 days. After 80 days, however, in this sample no full-sized corpora lutea of the original sets were found, and some were very small.

Ovulations occurred in two other females at 79 and 84 days, in agreement with the record of Loeb (1927). Full or partial opening of the vagina may take place without ovulation, even when large follicles are present. It is possible that such an incomplete oestrus may not be repeated for another interval of about 70 days, which would account for some of the long anovulatory periods which have been recorded. It is also possible that ovulation may occur without full vaginal opening (as can happen after an LH injection), and thus escape observation. Ovulation without oestrus has been recorded in the hysterectomized sheep (Kiracofe \& Spies, 1966).

It is surprising that corpora lutea which have lost two-thirds and more of their volume, and show histological regression, should still produce enough progesterone to inhibit ovulation and to maintain mucified vaginal epithelium for indefinite periods. Heap, Perry \& Rowlands (1967) observed that the concentration of progesterone in luteal tissue had already fallen from $53 \mathrm{ng} / \mathrm{mg}$ to $17 \mathrm{ng} / \mathrm{mg}$ by 50 days after hysterectomy. Possibly the secretions of the waning corpora lutea are supplemented by an interstitial cell progestagen. 
The independent regression of the induced and original corpora lutea in this experiment, like that of the induced and original ones in hysterectomized sheep (Kiracofe \& Spies, 1966) shows clearly that their duration and functional condition are not determined exclusively by the absence of the uterus, or by possible luteotrophic gonadotrophins. The original corpora lutea may still be of full size (Table 2, PH 59) up to 4 weeks after an induced ovulation, although they are regressed ( $\mathrm{PH} 88$ ) or absent ( $\mathrm{PH}$ 63) in other similarly treated animals hysterectomized for a longer time. Corpora lutea appear to have an intrinsic though variable life-span, their metabolism gradually becoming less active as they age.

\section{ACKNOWLEDGMENTS}

The first author gratefully acknowledges a grant from the Medical Research Council and the hospitality of the Agricultural Research Council.

The National Institutes of Health, Bethesda are thanked for a supply of luteinizing hormone NIH-LH-s 10.

\section{REFERENCES}

Deanesly, R. (1966) The effects of purified sheep luteinizing hormone on the guinea-pig ovary. 7. Reprod. Fert. 11, 303.

DEANESLY, R. (1967) Normal growth and persistence of corpora lutea of both ovaries in the unilaterally pregnant guinea-pig. J. Reprod. Fert. 14, 519.

DEANESLY, R. (1968) The effects of progesterone, testosterone and ergocornine on non-pregnant and pregnant guinea-pigs. J. Reprod. Fert. 16, 271.

Fischer, T. (1967) Local uterine regulation of the corpus luteum. Am. F. Anat. 121, 425.

Heap, R. B., Perry, J. S. \& Rowlands, I. W. (1967) Corpus luteum function in the guinea-pig; arterial and luteal progesterone levels and the effects of hysterectomy and hypophysectomy. 7. Reprod. Fert. 13, 537.

Hilliard, J., Spies, H. G. \& Sawyer, G. H. (1968) Cholesterol storage and progestin secretion during pregnancy and pseudopregnancy in the rabbit. Endocrinology, 82, 157.

HowE, G. R. (1965) Influence of the uterus upon cyclic ovarian activity in the guinea-pig. Endocrinology, 77,412 .

Inskeep, E. K., Oloufa, M. M., Pope, A. L. \& Casida, L. E. (1963) Functional capabilities of experimentally induced corpora lutea in ewes. F. Anim. Sci. 22, 159.

KIRACOFE, G. H. \& Sirs, H. G. (1966) Length of maintenance of naturally formed and experimentally induced corpora lutea in hysterectomized ewes. 7. Reprod. Fert. 11, 275.

LOEB, L. (1927) The effects of hysterectomy on the system of sex organs and on the periodicity of the sexual cycle in the guinea-pig. Am. F. Physiol. 83, 202.

Neill, J. D. \& DAy, B. N. (1964) Relationship of developmental stage to regression of the corpus luteum in swine. Endocrinology, 74, 355.

Rowlands, I. W. (1961) Effect of hysterectomy at different stages in the life cycle of the corpus luteum in the guinea-pig. F. Reprod. Fert. 2, 341. 